Vansenne, F., Borgie, C.A.J.M. de, Korevaar, J.C., Franssen, M.T.M., Pajkrt, E., Hansson, K.B.M/n Leschot, N.J., Bossuyt, P.M.M., Veen, F. van der, Goddijn, M. Low uptake of prenatal diagnosis after established carrier status of a balanced structural chromosome abnormality in couples with recurrent miscarriage. Fertility and Sterility: 2010, 94(1), 296-300

\begin{tabular}{|l|l|}
\hline $\begin{array}{l}\text { Postprint } \\
\text { Version }\end{array}$ & 1.0 \\
\hline Journal website & http://www.fertstert.org/article/S0015-0282(09)00376-8/abstract \\
\hline Pubmed link & http://www.ncbi.nlm.nih.gov/pubmed/19328468 \\
\hline DOI & $10.1016 /$ j.fertnstert.2009.02.020 \\
\hline
\end{tabular}

This is a NIVEL certified Post Print, more info at http://www.nivel.eu

\title{
Low uptake of prenatal diagnosis after established carrier status of a balanced structural chromosome abnormality in couples with recurrent miscarriage
}

Fleur VAnsenne M.D. ${ }^{A, \mathrm{~B}}$ „, Corianne A.J.M. De Borgie M.D., Ph.D. ${ }^{\mathrm{A}}$, Johanna C.

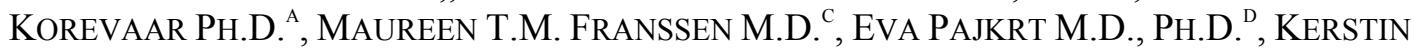
B.M. HANSSON Ph.D. ${ }^{\mathrm{E}}$, Nico J. LesChOT M.D., Ph.D. ${ }^{\mathrm{B}}$, PATRICK M.M. BossuYT M.D., Ph.D. ${ }^{A}$, Fulco VAn Der Veen M.D., Ph.D. ${ }^{\mathrm{C}}$ AND MARIËtTe GoddiJn M.D., Ph.D. ${ }^{\mathrm{C}}$

${ }^{a}$ Department of Clinical Epidemiology, Biostatistics and Bioinformatics, Academic Medical Centre, University of Amsterdam, Amsterdam, the Netherlands

${ }^{b}$ Department of Clinical Genetics, Academic Medical Centre, University of Amsterdam, Amsterdam, the Netherlands

${ }^{c}$ Centre for Reproductive Medicine, Department of Obstetrics and Gynecology, Academic Medical Centre, University of Amsterdam, Amsterdam, the Netherlands

${ }^{d}$ Department of Obstetrics and Gynecology, Academic Medical Centre, University of Amsterdam, Amsterdam, the Netherlands

e Department of Clinical Genetics, Leiden University Medical Centre, Leiden, the Netherlands

Objective To evaluate to what extent couples carrying a balanced structural chromosome abnormality follow up the advice to opt for invasive prenatal diagnosis (PND) in subsequent pregnancies.

Design Index-control study.

Setting Six centers for Clinical Genetics in The Netherlands.

Patient(s) Couples referred for chromosome analysis after recurrent miscarriage between 1992 and 2001 and with at least one pregnancy after disclosure; 239 carrier couples and 389 noncarrier couples.

Intervention(s) Questionnaire, medical record checking.

Main Outcome Measure(s)

Uptake of invasive PND.

Result(s) Only 53 of 239 (22\%) carrier couples underwent a PND procedure (CVS or amniocentesis) in all subsequent pregnancies. A relatively high number, 105 (44\%) carrier couples, refrained from PND in all subsequent pregnancies. More carrier couples with maternal age $\geq 36$ years $(20 / 33=61 \%)$ refrained from PND, compared with carrier couples with maternal age $<36$ years $(85 / 206=41 \%)$. In women $\geq 36$ years, an equal proportion of carrier and noncarrier couples refrained from PND (61\% vs. 54\%).

Conclusion(s) The advice to opt for invasive PND in carrier couples is poorly followed, especially in carrier couples with maternal age $\geq 36$ years. The motivations of carrier couples to opt for or refrain from invasive PND 
Vansenne, F., Borgie, C.A.J.M. de, Korevaar, J.C., Franssen, M.T.M., Pajkrt, E., Hansson, K.B.Mm Leschot, N.J., Bossuyt, P.M.M., Veen, F. van der, Goddijn, M. Low uptake of prenatal diagnosis after established carrier status of a balanced structural chromosome abnormality in couples with recurrent miscarriage. Fertility and Sterility: 2010, 94(1), 296-300

procedures should be the topic for further research to optimize clinical care and informative decision making.

The reported incidence of one of the partners carrying a balanced structural chromosome abnormality in couples with two or more miscarriages varies between 3\% and $6 \%$ (1), (2) and (3). In these carrier couples, products of conception can have a normal karyotype, the same balanced structural chromosome abnormality as the carrier, or an unbalanced structural chromosome abnormality. The latter can lead to miscarriage, a stillborn child, or a child born with major congenital defects and severe mental handicaps.

Guidelines for the management of recurrent miscarriage (RM) recommend parental chromosome analysis in couples with an increased a priori risk of carrying a structural chromosome abnormality (4), (5), (6) and (7). Once a structural chromosome abnormality has been detected, several guidelines emphasize the importance of invasive prenatal diagnosis (PND), and couples are advised to undergo either chorionic villus sampling (CVS) or amniocentesis for fetal karyotyping in subsequent pregnancies. In case of an unbalanced fetal karyotype, termination of the pregnancy can be considered after careful and thorough counseling.

Because parental chromosome analysis is offered to prevent the birth of a live-born handicapped child, the detection of carrier status would suggest a likelihood of a high number of PND procedures in subsequent pregnancies. Data on how couples act upon the disclosure of parental carrier status are lacking, and therefore, the effectiveness of routinely offering parental chromosome analysis in clinical care is unknown.

The aim of this study was to investigate the uptake of invasive prenatal diagnostic procedures by carrier couples in subsequent pregnancies, and to compare results in carrier couples with advanced maternal age ( $\geq 36$ years) with the uptake in noncarrier couples with advanced maternal age.

\section{MATERIALS AND METHODS}

The data for this research was collected in a study of consecutive couples referred for parental chromosome analysis after two or more miscarriages in six centers for Clinical Genetics in the Netherlands between January 1992 and January 2001 (2) and (8).

We selected all couples in which one of the partners was found to carry a structural chromosome abnormality, and identified them as carrier couples. For each carrier couple a random subset of two noncarrier couples was formed by identifying the last couple tested before the carrier couple and the first couple tested after the carrier couple in each center. This matching was performed to obtain a sample balanced over time. Institutional review board approval was requested and obtained.

Eligible couples were contacted by mail and invited to participate. Initial nonresponders received reminders. After written informed consent, the medical records of the clinical departments were examined, and couples were asked to complete a questionnaire.

We then selected all carrier and noncarrier couples who became pregnant at least once after, or were pregnant (gestational age $<10$ weeks) during the moment of disclosure of the result of the parental chromosome analysis, as these couples are potential candidates for invasive PND in current or subsequent pregnancies.

Obstetric follow-up was recorded for a minimum of 24 months after initial parental chromosome analysis. An ongoing pregnancy was defined as a viable intrauterine pregnancy with an observed positive heartbeat at 11 to 12 weeks gestational age.

\section{Analysis}

For each included couple, we registered whether they had one or more pregnancies after disclosure, and whether they had opted for invasive PND in those pregnancies. We also recorded if they had opted for CVS or amniocentesis. 
Vansenne, F., Borgie, C.A.J.M. de, Korevaar, J.C., Franssen, M.T.M., Pajkrt, E., Hansson, K.B.Mm Leschot, N.J., Bossuyt, P.M.M., Veen, F. van der, Goddijn, M. Low uptake of prenatal diagnosis after established carrier status of a balanced structural chromosome abnormality in couples with recurrent miscarriage. Fertility and Sterility: 2010, 94(1), 296-300

In carriers, a subanalysis of maternal age at time of parental chromosome analysis was performed, resulting in a young maternal age group ( $<36$ years) and an advanced maternal age group ( $\geq 36$ years).

In routine clinical management in the Netherlands women are eligible for invasive PND from a maternal age of 36 years or older because of their increased risk of having a child with Down syndrome. For them, all invasive PND procedures are fully covered by health insurance. Women with a maternal age $<36$ years requesting invasive PND for personal reasons will have to pay for the procedures themselves.

Therefore, carrier couples with advanced maternal age ( $\geq 36$ years) were compared with noncarrier couples with advanced maternal age ( $\geq 36$ years).

Differences within carrier couple subgroups and between carrier couples and noncarrier couples were tested with the Student's $t$ test for parametric continuous variables, the MannWhitney U test or Kruskal Wallis test for nonparametric continuous variables and the chisquare for categoric variables. P values $<0.05$ were considered to indicate statistical significance. All statistical analyses were performed using SPSS version 15.0 (SPSS Inc., Chicago, IL).

\section{RESULTS}

We identified 239 carrier couples and 389 noncarrier couples. The baseline characteristics of the carrier and the noncarrier group are summarized in Table 1. Both groups were comparable in relation to maternal age, mean number of pregnancies and miscarriages, and uptake of invasive PND procedures before parental chromosome analysis. Results of conventional parental karyotyping in carrier couples are described in Appendix 1 (available online).

The results of the obstetric follow-up after disclosure of the parental chromosome analysis are summarized in Table 2. The median follow-up period was 66 months (interquarterile range 42-96 months). The carrier group had a mean number of 1.4 ongoing pregnancies after disclosure.

\section{[TABLE 1][TABLE 2]}

In total, 556 pregnancies were confirmed in the 239 carrier couples, of which 328 were ongoing pregnancies. In 184 (56\%) of these 328 ongoing pregnancies invasive PND was performed. This was done by means of CVS in $55(30 \%)$ pregnancies and by amniocentesis in $129(70 \%)$ pregnancies. Overall, $53(22 \%)$ carrier couples underwent an invasive PND procedure in all subsequent pregnancies. In $81(34 \%)$ carrier couples invasive PND was performed in at least one, but not in all, subsequent pregnancies; 105 (44\%) carrier couples refrained from any invasive PND procedure in all their subsequent pregnancies.

Subsequently, we evaluated the influence of maternal age on PND uptake. The results are summarized in Figure 1. Carrier couples with advanced maternal age ( $\geq 36$ years) had refrained significantly more often from invasive PND than younger carrier couples $(\mathrm{P}=.03)$ : $61 \%$ of carrier couples with advanced maternal age had never undergone an invasive PND procedure in a subsequent pregnancy, versus $41 \%$ of younger carrier couples. In carrier couples with advanced maternal age $23 \%$ had undergone invasive PND in every subsequent pregnancy versus $18 \%$ of younger carrier couples $(\mathrm{P}=.55)$.

\section{[FIGURE 1]}

Within the couples with advanced maternal age ( $\geq 36$ years) there was no difference in the uptake of invasive PND procedures between carrier couples and noncarrier couples. More than half (54\%) of the noncarrier couples with advanced maternal age refrained from any 
Vansenne, F., Borgie, C.A.J.M. de, Korevaar, J.C., Franssen, M.T.M., Pajkrt, E., Hansson, K.B.Mm Leschot, N.J., Bossuyt, P.M.M., Veen, F. van der, Goddijn, M. Low uptake of prenatal diagnosis after established carrier status of a balanced structural chromosome abnormality in couples with recurrent miscarriage. Fertility and Sterility: 2010, 94(1), 296-300

invasive PND procedure, compared with $61 \%$ of carrier couples with advanced maternal age $(\mathrm{P}=.51)$.

\section{DISCUSSION}

We found in this study that many couples with an established structural chromosome abnormality refrained from invasive PND procedures (CVS or amniocentesis) in subsequent pregnancies. Thus, although all couples underwent genetic counseling where the need for PND was stressed, many disregarded this advice. Overall, almost half of the carrier couples in our study group underwent no invasive PND procedures in all subsequent ongoing pregnancies. In the subgroup of carrier couples with advanced maternal age ( $\geq 36$ years) $>60 \%$ decided against any type of invasive PND. We have not collected any data on the motivations of carrier couples to refrain from invasive PND procedures.

The data presented in this study are based on the inclusion of carrier couples evaluated between 1992 and 2001, with follow-up of subsequent pregnancies and accompanying invasive PND procedures until the end of 2003. Results should be interpreted with regard to the routine clinical care provided during that period. At that time little debate existed on parental chromosome analysis in case of RM. From that perspective, it is even more surprising that women refrained in such a high percentage from additional invasive PND. At present, it is well known that parental chromosome analysis can be withheld in low risk couples, and that the chances of having a live-born handicapped child with an unbalanced structural chromosome abnormality are very low in couples with RM. In our dataset, in total four unbalanced fetal karyotypes were found in $550(0.7 \%)$ pregnancies in 278 carrier couples. Three of the four unbalanced karyotypes were detected at invasive PND, and subsequently, two fetuses were aborted. The third pregnancy was not terminated, and the child died immediately after birth at 43 weeks of gestation because of severe handicaps. One unbalanced fetus with severe congenital abnormalities was born after the parents had decided to refrain from invasive PND after a normal ultrasound examination in the second trimester. This child is still alive (8).

The risk of an unbalanced fetus for a carrier couple varies according to the breakpoints of the chromosomes involved in the parental translocation. This risk was at that time estimated between 3\% and 5\% (9) and (10). Generally, we can assume that all carrier couples were informed of their individual increased risk and advised to opt for invasive PND. About onethird (36\%) of carrier couples underwent an invasive PND procedure in at least one, but not all, subsequent pregnancies, suggesting there are other reasons for them to opt for or refrain from invasive PND procedures than just the risk given during counseling. In a study by Sawyer et al. (11) it was shown that reproductive choices of carriers of cystic fibrosis were dynamic over time, with decisions and views changing (11).

It is possible that couples make different choices today regarding the uptake of invasive PND, because of developments in PND procedures or differences in counseling after disclosure of the test result. Therefore, it may well be that the uptake at present is even lower. This might also be reinforced by the introduction of first trimester screening (combined test) for Down syndrome in the last few years.

Couples with a balanced chromosome abnormality today can opt for in vitro fertilization (IVF) combined with preimplantation genetic diagnosis (PGD) as an alternative to PND (12) and (13). In our study none of the carrier couples opted for IVF-PGD, probably mainly because between 1993 and 2001, knowledge about IVF-PGD was not widespread. The current uptake of IVF-PGD in carrier couples with RM is unknown. Reported data from the ESHRE-PGD consortium on carrier couples with RM cannot be separated from couples with other indications (14). Given these new techniques, an even further reduced uptake of invasive PND in carrier couples could be expected now and in the future.

In the literature, limited data can be found regarding the uptake of invasive PND procedures after parental chromosome analysis. Previous studies presented the results as the (percentage 
Vansenne, F., Borgie, C.A.J.M. de, Korevaar, J.C., Franssen, M.T.M., Pajkrt, E., Hansson, K.B.Mm Leschot, N.J., Bossuyt, P.M.M., Veen, F. van der, Goddijn, M. Low uptake of prenatal diagnosis after established carrier status of a balanced structural chromosome abnormality in couples with recurrent miscarriage. Fertility and Sterility: 2010, 94(1), 296-300

of) pregnancies in which PND was performed as a unit of analysis, whereas we took the couples as a unit of analysis. One study found a lower uptake of amniocentesis: in 14 of 58 (24\%) subsequent pregnancies in carrier couples (15). Two further studies found the uptake of amniocentesis in carrier couples to be 26 of $43(60 \%)$ and 23 of $34(67 \%)$ in subsequent pregnancies (16) and (17). All three previous studies are based on small numbers of carrier couples, and none looked at differences in uptake of invasive PND related to maternal age or the motivations of the couples to opt for or refrain from invasive PND.

In carrier couples with advanced maternal age ( $\geq 36$ years) there was remarkably an even higher proportion of couples refraining from invasive PND, even though mothers at advanced age have an increased risk for fetal aneuploidy, especially Down syndrome. No difference existed in the uptake of invasive PND procedures between carrier and noncarrier couples with advanced maternal age ( $\geq 36$ years). This shows that an established carrier status is not an additional reason to opt for invasive PND in older women.

At this moment we can only speculate why carrier couples refrain from invasive PND. Couples might decide in advance that they will not choose to terminate their pregnancy, regardless of the possiblility of a handicapped child because of religious or personal beliefs. Another motive of carrier couples could be the desire to avoid invasive tests at all costs because of its concomitant risk of inducing pregnancy loss. Couples were told the risk of inducing pregnancy loss as a consequence of invasive PND was between $0.5 \%$ and $1.0 \%$ according to the literature (18). In our study there were no induced pregnancy losses after invasive procedures. Two previous studies reported a significantly lower uptake of invasive PND in women pregnant after assisted conception compared with women with a spontaneous conception. Regardless of their age, these women weighed the risk of an invasive PND procedure heavily as their pregnancy was very precious, and they felt that they may not have the chance to ever have another child (19) and (20). These feelings might also apply to our study population. In the Netherlands, an overall decline in uptake of invasive PND procedures among women above 36 years of age has been reported earlier. The percentage of women with advanced maternal age undergoing an invasive PND procedure fell from $46 \%$ in 1991 to $34 \%$ in 2000 (21). These percentages are comparable with the results in our study. A study published in 2002 found that the key determinant regarding the uptake of invasive PND in women aged 35 years or older was their a priori opinion regarding invasive PND and not their increased risk of a child with a chromosome abnormality (22).

To improve genetic counseling and clinical care, understanding of the motivations of carrier couples is essential. Additional research is needed into the reasons why carrier couples decide to refrain from invasive PND.

\section{ACKNOWLEDGMENTS}

F.V. analyzed the data and wrote the article. C.A.J.M.d.B., P.M.M.B., M.G., and J.C.K. helped with the statistics and interpretation of the data. M.T.M.F. and K.B.M.H. collected the data. M.G. had the idea for the study and developed the study design with F.v.d.V., P.M.M.B., and N.J.L. E.P. provided intellectual input and help with interpretation of data. All authors revised the article.

\section{REFERENCES}

1 M. Braekeleer and T.N. de Dao, Cytogenetic studies in couples experiencing repeated pregnancy losses, Hum Reprod 5 (1990), pp. 519-528.

2 M.T. Franssen, J.C. Korevaar, N.J. Leschot, P.M. Bossuyt, A.C. Knegt and K.B. GerssenSchoorl et al., Selective chromosome analysis in couples with two or more miscarriages: case-control study, BMJ 331 (2005), pp. 137-141.

3 E.B. Hook, N.P. Healy and A.M. Willey, How much difference does chromosome banding make? Adjustments in prevalence and mutation rates of human structural cytogenetic abnormalities, Ann Hum Genet 53 (1989), pp. 237-242. 
Vansenne, F., Borgie, C.A.J.M. de, Korevaar, J.C., Franssen, M.T.M., Pajkrt, E., Hansson, K.B.Mm Leschot, N.J., Bossuyt, P.M.M., Veen, F. van der, Goddijn, M. Low uptake of prenatal diagnosis after established carrier status of a balanced structural chromosome abnormality in couples with recurrent miscarriage. Fertility and Sterility: 2010, 94(1), 296-300

4 , American College of Obstetricians and Gynaecologists. Management of recurrent pregnancy loss, Int J Gynaecol Obstet 78 (2002), pp. 179-190.

5 , Dutch Society of Obstetricians and Gynecologists, Recurrent miscarriage. Guideline 20. Utrecht: NVOG (2007).

6 E. Jauniaux, R.G. Farquharson, O.B. Christiansen and N. Exalto, Evidence-based guidelines for the investigation and medical treatment of recurrent miscarriage, Hum Reprod 21 (2006), pp. 2216-2222.

7 , Royal College of Obstetricians and Gynaecologists. The investigation of and treatment of couples with recurrent miscarriage (Guideline no. 17), RCOG, London (2003).

8 M.T. Franssen, J.C. Korevaar, F. van der Veen, N.J. Leschot, P.M. Bossuyt and M. Goddijn, Reproductive outcome after chromosome analysis in couples with two or more miscarriages: index-control study, BMJ 332 (2006), pp. 759-763.

9 A. Boue and P. Gallano, A collaborative study of the segregation of inherited chromosome structural rearrangements in 1356 prenatal diagnoses, Prenat Diagn 4 (1984), pp. 45-67.

10 A. Daniel, E.B. Hook and G. Wulf, Risks of unbalanced progeny at amniocentesis to carriers of chromosome rearrangements: data from the United States and Canadian laboratories, Am J Med Genet 33 (1989), pp. 14-53.

11 S.M. Sawyer, B. Cerritelli, L.S. Carter, M. Cooke, J.A. Glazner and J. Massie, Changing their minds with time: a comparison of hypothetical and actual reproductive behaviors in parents of children with cystic fibrosis, Pediatrics 118 (2006), pp. e649-e656.

12 J.P. Geraedts, J.C. Harper, P. Braude, K. Sermon, A. Veiga and L. Gianaroli et al., Preimplantation genetic diagnosis (PGD), a collaborative activity of clinical genetic departments and IVF centres, Prenat Diagn 21 (2001), pp. 1086-1092.

13 K. Sermon, A. Van Steirteghem and I. Liebaers, Preimplantation genetic diagnosis, Lancet 363 (2004), pp. 1633-1641.

14 V. Goossens, G. Harton, C. Moutou, P.N. Scriven, J. Traeger-Synodinos and K. Sermon et al., ESHRE PGD Consortium data collection VIII: cycles from January to December 2005 with pregnancy follow-up to October 2006, Hum Reprod 23 (2008), pp. 2629-2645.

15 M.D. Stephenson and S. Sierra, Reproductive outcomes in recurrent pregnancy loss associated with a parental carrier of a structural chromosome rearrangement, Hum Reprod 21 (2006), pp. 1076-1082.

16 M. Goddijn, J.H. Joosten, A.C. Knegt, F. van der Veen, M.T. Franssen and G.J. Bonsel et al., Clinical relevance of diagnosing structural chromosome abnormalities in couples with repeated miscarriage, Hum Reprod 19 (2004), pp. 1013-1017.

17 M. Sugiura-Ogasawara, Y. Ozaki, T. Sato, N. Suzumori and K. Suzumori, Poor prognosis of recurrent aborters with either maternal or paternal reciprocal translocations, Fertil Steril 81 (2004), pp. 367-373.

18 A. Tabor, J. Philip, M. Madsen, J. Bang, E.B. Obel and B. Norgaard-Pedersen, Randomised controlled trial of genetic amniocentesis in 4606 low-risk women, Lancet 1 (1986), pp. 1287-1293.

19 A. Geipel, U. Gembruch, M. Ludwig, U. Germer, E. Schwinger and A. Dormeier et al., Genetic sonography as the preferred option of PND in patients with pregnancies following intracytoplasmic sperm injection, Hum Reprod 14 (1999), pp. 2629-2634.

20 D. Meschede, B. Lemcke, J. Stussel, F. Louwen and J. Horst, Strong preference for noninvasive PND in women pregnant through intracytoplasmic sperm injection (ICSI), Prenat Diagn 18 (1998), pp. 700-705.

21 H.T. Nagel, A.C. Knegt, M.D. Kloosterman, H.I. Wildschut, N.J. Leschot and F.P. Vandenbussche, Invasive PND in The Netherlands, 1991-2000: number of procedures, indications and abnormal results detected, Ned Tijdschr Geneeskd 148 (2004), pp. 15381543.

22 P. Vergani, A. Locatelli, A. Biffi, E. Ciriello, A. Zagarella and J.C. Pezzullo et al., Factors affecting the decision regarding amniocentesis in women at genetic risk because of age 35 years or older, Prenat Diagn 22 (2002), pp. 769-774.

\section{[APPENDIX 1]}


Vansenne, F., Borgie, C.A.J.M. de, Korevaar, J.C., Franssen, M.T.M., Pajkrt, E., Hansson, K.B.Mm Leschot, N.J., Bossuyt, P.M.M., Veen, F. van der, Goddijn, M. Low uptake of prenatal diagnosis after established carrier status of a balanced structural chromosome abnormality in couples with recurrent miscarriage. Fertility and Sterility: 2010, 94(1), 296-300

TABLES, FigURES AND APPENDIX

Table 1

\begin{tabular}{|c|c|c|}
\hline \multicolumn{3}{|c|}{$\begin{array}{l}\text { Baseline characteristics and obstetric history } \\
\text { of carrier couples and noncarrier couples } \\
\text { before parental chromosome analysis. }\end{array}$} \\
\hline & $\begin{array}{l}\text { Carrier } \\
\text { couples } \\
(n=239)\end{array}$ & $\begin{array}{l}\text { Noncarrier } \\
\text { couples } \\
(n=389)\end{array}$ \\
\hline \multicolumn{3}{|l|}{ Maternal age (y) } \\
\hline Mean (SD) & $32(4.3)$ & $32(5.0)$ \\
\hline Median (IQR) & $31(29-34)$ & $32(29-37)$ \\
\hline \multicolumn{3}{|l|}{ No. of pregnancies } \\
\hline Mean (SD) & $4.0(1.6)$ & $4.0(1.7)$ \\
\hline \multicolumn{3}{|l|}{ No. of miscarriages } \\
\hline Mean (SD) & $2.8(1.0)$ & $2.7(1.0)$ \\
\hline \multicolumn{3}{|l|}{$\begin{array}{l}\text { PND procedures } \\
\text { per pregnancy }\end{array}$} \\
\hline Mean (SD) & $0.04(0.1)$ & $0.06(0.1)$ \\
\hline $\begin{array}{c}\text { Maternal age } \\
<36 \mathrm{y}\end{array}$ & 0.03 & 0.02 \\
\hline $\begin{array}{l}\text { Maternal age } \\
\geq 36 \mathrm{y}\end{array}$ & 0.1 & 0.1 \\
\hline \multicolumn{3}{|c|}{$\begin{array}{l}\text { Note: } \mathrm{PND}=\text { prenatal diagnosis; } \mathrm{CVS}=\text { chorionic villus } \\
\text { sampling. } \\
\text { a Invasive PND procedures (CVS and amniocentesis). }\end{array}$} \\
\hline \multicolumn{3}{|c|}{ Vansenne. Low Uptake of PND. Fertil Steril 2010.} \\
\hline
\end{tabular}


Vansenne, F., Borgie, C.A.J.M. de, Korevaar, J.C., Franssen, M.T.M., Pajkrt, E., Hansson, K.B.Mm Leschot, N.J., Bossuyt, P.M.M., Veen, F. van der, Goddijn, M. Low uptake of prenatal diagnosis after established carrier status of a balanced structural chromosome abnormality in couples with recurrent miscarriage. Fertility and Sterility: 2010, 94(1), 296-300

Table 2

\begin{tabular}{|c|c|c|}
\hline \multicolumn{3}{|c|}{$\begin{array}{l}\text { Follow-up after disclosure of parental } \\
\text { chromosome analysis. }\end{array}$} \\
\hline $\begin{array}{l}\text { Pregnancy outcome } \\
\text { and PND uptake }\end{array}$ & $\begin{array}{l}\text { Carrier } \\
\text { couples } \\
(\mathrm{n}=239)\end{array}$ & $\begin{array}{l}\text { Noncarrier } \\
\text { couples } \\
(\mathrm{n}=389)\end{array}$ \\
\hline \multicolumn{3}{|l|}{$\begin{array}{l}\text { No. of subsequent } \\
\text { pregnancies }\end{array}$} \\
\hline Mean (SD) & $2.4(1.6)$ & $2.1(0.8)$ \\
\hline \multicolumn{3}{|l|}{$\begin{array}{l}\text { No. of subsequent } \\
\text { miscarriages }\end{array}$} \\
\hline Mean (SD) & $1.0(1.4)$ & $0.7(1.4)$ \\
\hline \multicolumn{3}{|l|}{$\begin{array}{l}\text { No. of ongoing } \\
\text { pregnancies }\end{array}$} \\
\hline Mean (SD) & $1.4(0.8)$ & $1.4(0.8)$ \\
\hline \multicolumn{3}{|l|}{$\begin{array}{l}\text { No. of PND procedures }{ }^{a} \\
\text { per ongoing } \\
\text { pregnancy }\end{array}$} \\
\hline Mean (SD) & $0.6(0.5)$ & $0.2(0.4)$ \\
\hline \multicolumn{3}{|c|}{$\begin{array}{l}\text { Note: PND = prenatal diagnosis; CVS = chorionic villus } \\
\text { sampling. } \\
\text { a Invasive PND procedures (CVS and amniocentesis). }\end{array}$} \\
\hline \multicolumn{3}{|c|}{ Vansenne. Low Uptake of PND. Feril Steril 2010.} \\
\hline
\end{tabular}


Vansenne, F., Borgie, C.A.J.M. de, Korevaar, J.C., Franssen, M.T.M., Pajkrt, E., Hansson, K.B.Mm Leschot, N.J., Bossuyt, P.M.M., Veen, F. van der, Goddijn, M. Low uptake of prenatal diagnosis after established carrier status of a balanced structural chromosome abnormality in couples with recurrent miscarriage. Fertility and Sterility: 2010, 94(1), 296-300

\section{Figure 1}

\section{FIGURE 1}

Uptake of PND-procedures (CVS or amniocentesis) by carrier and noncarrier couples in subsequent pregnancies after disclosure of parental chromosome analysis (\%), related to maternal age.

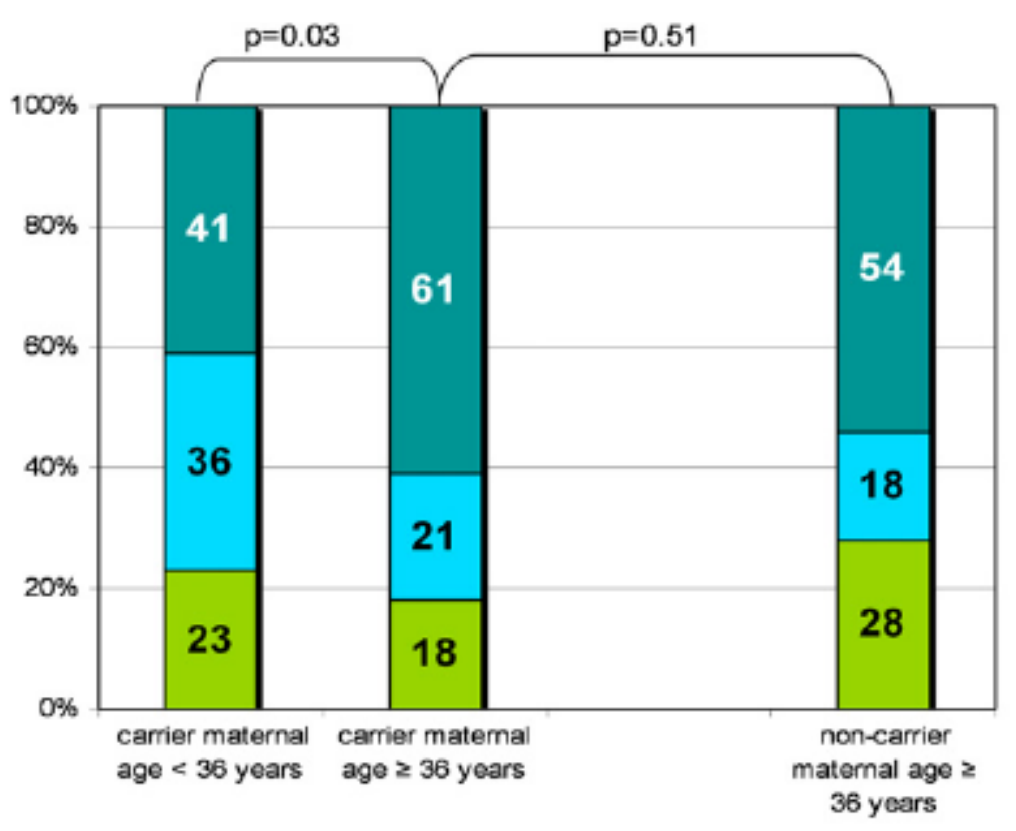

$\square$ every pregnancy $\square$ at least once but not every pregnancy $\square$ never

Vansenne. Low Uptake of PND. Fertil Steril 2010. 
Vansenne, F., Borgie, C.A.J.M. de, Korevaar, J.C., Franssen, M.T.M., Pajkrt, E., Hansson, K.B.M/m Leschot, N.J., Bossuyt, P.M.M., Veen, F. van der, Goddijn, M. Low uptake of prenatal diagnosis after established carrier status of a balanced structural chromosome abnormality in couples with recurrent miscarriage. Fertility and Sterility: 2010, 94(1), 296-300

\section{Appendix 1}

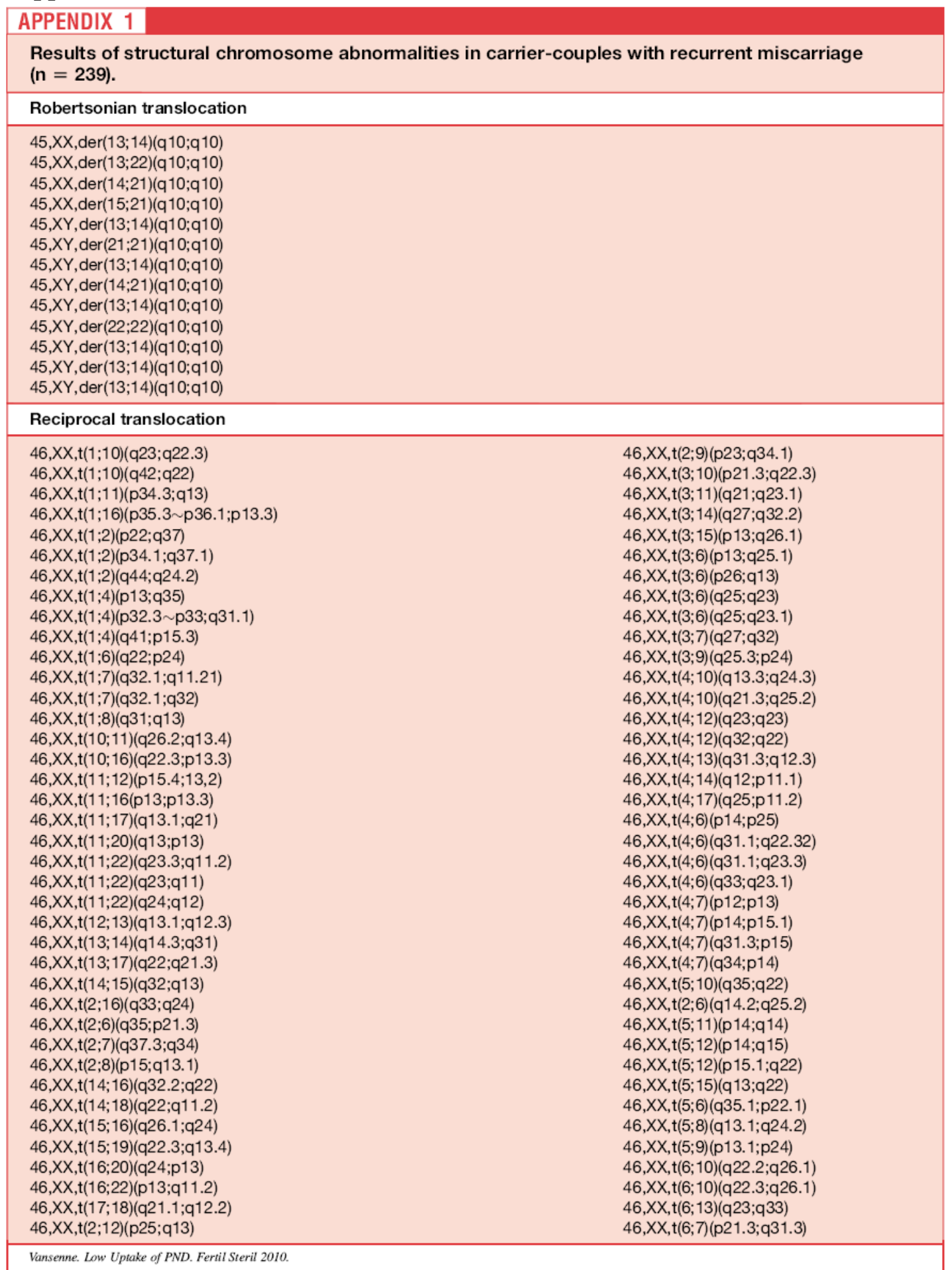


Vansenne, F., Borgie, C.A.J.M. de, Korevaar, J.C., Franssen, M.T.M., Pajkrt, E., Hansson, K.B.Mm Leschot, N.J., Bossuyt, P.M.M., Veen, F. van der, Goddijn, M. Low uptake of prenatal diagnosis after established carrier status of a balanced structural chromosome abnormality in couples with recurrent miscarriage. Fertility and Sterility: 2010, 94(1), 296-300

\begin{tabular}{|c|c|}
\hline \multicolumn{2}{|l|}{ Continued. } \\
\hline \multicolumn{2}{|l|}{ Reciprocal translocation } \\
\hline $46, X X, t(2 ; 13)(q 33.1 ; q 32)$ & $46, X Y, t(12 ; 15)(q 13.1 ; q 25)$ \\
\hline $46, X X, t(2 ; 14)(q 33.1 ; q 32.3)$ & $46, X Y, t(2 ; 4)(q 12 ; q 31.3)$ \\
\hline $46, X X, t(2 ; 15)(q 33 ; q 15)$ & $46, X Y, t(9 ; 17)(q 12 ; p 11.21)$ \\
\hline $46, X X, t(6 ; 8)(q 25.1 ; q 23)$ & $46, X Y, t(4 ; 5)(q 23 ; q 35.3)$ \\
\hline $46, X X, t(6 ; 8)(q 26 ; q 24.1)$ & $46, X Y, t(6 ; 18)(q 23 ; p 11.2)$ \\
\hline $46, X X, t(7 ; 12)(p 14 ; q 14)$ & $46, X Y, t(4 ; 15)(p 14 ; q 13)$ \\
\hline $46, X X, t(8 ; 11)(q 22.1 ; p 11)$ & $46, \mathrm{XY}, \mathrm{t}(7 ; 17)(\mathrm{p} 15.1 ; \mathrm{q} 25)$ \\
\hline $46, \mathrm{XX}, \mathrm{t}(8 ; 17)(\mathrm{p} 11.1 ; \mathrm{p} 11.1)$ & $46, X Y, t(7 ; 13)(q 11.23 ; q 14.3)$ \\
\hline $46, X X, t(8 ; 22)(q 24.1 ; q 11.2)$ & $46, X Y, t(3 ; 4)(p 24.2 ; q 31.3)$ \\
\hline $46, X X, t(9 ; 13)(q 34 ; q 32)$ & $46, X Y, t(3 ; 5)(q 13.3 ; p 15.2)$ \\
\hline $46, X X, t(9 ; 17)(p 13 ; q 23)$ & $46, X Y, t(1 ; 11)(p 32.1 ; q 23.3)$ \\
\hline $46, X X, t(3 ; 6)(q 26 ; q 24)$ & $46, X Y, t(6 ; 10)(p 23 ; q 24.3)$ \\
\hline $46, \mathrm{XY}, \mathrm{t}(8 ; 12)(\mathrm{p} 23.1 ; \mathrm{p} 13.3)$ & $46, \mathrm{XY}, \mathrm{t}(12 ; 18)(\mathrm{q} 21.2 ; \mathrm{q} 22.2)$ \\
\hline $46, X Y, t(11 ; 21)(p 15.4 ; q 22.1)$ & $46, X Y, t(3 ; 6)(q 25 ; q 23)$ \\
\hline $46, X Y, t(1 ; 3)(q 21 ; q 25)$ & $46, X Y, t(1 ; 5)(p 22 ; p 13)$ \\
\hline $46, X Y, t(5 ; 17)(q 33.1 ; q 25.3)$ & $46, X Y, t(8 ; 16)(q 24.3 ; q 22)$ \\
\hline $46, X Y, t(10 ; 13)(q 23.3 ; q 13)$ & $46, X Y, t(3 ; 8)(q 12 ; q 24.1)$ \\
\hline $46, X Y, t(5 ; 12)(q 35.1 ; q 24.1)$ & $46, X Y, t(1 ; 6)(p 34.3 ; p 23)$ \\
\hline $46, X Y, t(6 ; 16)(q 25.3 ; p 13.3)$ & $46, \mathrm{XY}, \mathrm{t}(10 ; 13)(\mathrm{p} 11.2 ; \mathrm{q} 31.2)$ \\
\hline $46, X Y, t(4 ; 7)(q 32 ; p 14)$ & $46, X Y, t(3 ; 8)(p 13 ; q 24.1)$ \\
\hline $46, X Y, t(16 ; 21)(p 11.2 ; q 22.3)$ & $46, \mathrm{XY}, \mathrm{t}(11 ; 14)(\mathrm{q} 14.2 ; \mathrm{q} 31)$ \\
\hline $46, X Y, t(2 ; 7)(q 33 ; q 36)$ & $46, X Y, t(14 ; 16)(q 32.3 ; p 13)$ \\
\hline $46, X Y, t(11 ; 21)(q 14 ; q 21)$ & $46, \mathrm{XY}, \mathrm{t}(14 ; 17)(\mathrm{q} 12 ; \mathrm{q} 21)$ \\
\hline $46, X Y, t(3 ; 4)(q 23.1 ; p 15.1)$ & $46, X Y, t(4 ; 12)(q 33 ; q 22)$ \\
\hline $46, X Y, t(6 ; 20)(q 15 ; p 12.2)$ & $46, X Y, t(8 ; 11)(p 21.3 ; q 25)$ \\
\hline $46, \mathrm{XY}, \mathrm{t}(1 ; 11)(\mathrm{p} 34.1 ; \mathrm{q} 13.3)$ & $46, X Y, t(3 ; 20)(p 10 ; p 10)$ \\
\hline $46, X Y, t(1 ; 2)(q 42.3 ; q 33.1)$ & $46, X Y, t(1 ; 12)(q 42 ; q 15)$ \\
\hline $46, X Y, t(11 ; 16)(p 11.2 ; q 22.1)$ & $46, X Y, t(3 ; 8)(q 21 ; p 11)$ \\
\hline $46, X Y, t(17 ; 22)(q 25.3 ; q 12.2)$ & $46, X Y, t(4 ; 22)(q 12 ; p 13)$ \\
\hline $46, X Y, t(4 ; 18)(q 31.3 ; q 21.3)$ & $46, X Y, t(1 ; 2)(p 31.2 ; p 13)$ \\
\hline $46, X Y, t(7 ; 10)(q 32 ; q 22)$ & $46, X Y, t(3 ; 18)(q 27 ; p 11.1)$ \\
\hline $46, X Y, t(4 ; 10)(q 21.1 ; q 25.2)$ & $46, \mathrm{XY}, \mathrm{t}(4 ; 8)(\mathrm{q} 33 ; \mathrm{q} 11.2)$ \\
\hline $46, X Y, t(9 ; 10)(q 13 ; q 1.12)$ & $46, \mathrm{XY}, \mathrm{t}(7 ; 14)(\mathrm{q} 11.23: \mathrm{q} 24.3)$ \\
\hline $46, \mathrm{XY}, \mathrm{t}(3 ; 11)(\mathrm{q} 25.1 ; \mathrm{p} 15.1)$ & $46, X Y, t(6 ; 20)(q 23.1 ; q 13.3)$ \\
\hline $46, X Y, t(5 ; 17)(q 33.3 ; p 13)$ & $46, X Y, t(2 ; 13)(q 35 ; q 32)$ \\
\hline $46, X Y, t(11 ; 22)(q 23.3 ; q 11.2)$ & $46, X X, \operatorname{der}(22) t(Y ; 22)(q 12 ; p 12 / 13)$ \\
\hline $46, X Y, t(14 ; 19)(q 24.1 ; q 13.4)$ & $46, \mathrm{XX}, \operatorname{der}(22) \mathrm{t}(\mathrm{Y} ; 22)(\mathrm{q} 12 ; \mathrm{p} 13)$ \\
\hline $46, X Y, t(1 ; 6)(p 36.3 ; p 22.2)$ & $46, X Y, t(1 ; 10)(q 42.2 ; p 12.2)$ \\
\hline $46, X Y, t(18 ; 20)(p 11.1 ; p 11.1)$ & $46, X Y, t(8 ; 10)(p 21.3 ; q 24.3)$ \\
\hline $46, X Y, t(2 ; 9)(q 14.2 ; p 24)$ & $46, X Y, t(6 ; 7)(p 21.3 ; p 15.3)$ \\
\hline \multirow{3}{*}{\multicolumn{2}{|c|}{$\begin{array}{l}46, X X, t(3 ; 4)(p 14.2 ; q 35) \\
46, X Y, t(8 ; 10)(p 23.1 ; p 11.3) \\
46, X Y, t(4 ; 9)(p 12 ; p 22)\end{array}$}} \\
\hline & \\
\hline & \\
\hline Paracentric inversion & Pericentric inversion \\
\hline $46, X X, \operatorname{inv}(11)(q 21 q 23)$ & $46, X X, \operatorname{inv}(1)(p 11 q 21)$ \\
\hline $46, X X$, inv $(12)(q 11 q 23)$ & $46, X X$, inv(11)(p11.1q12.3) \\
\hline $46, X X, \operatorname{inv}(12)(q 15 q 24.1)$ & $46, X X, \operatorname{inv}(2)(p 11 q 13)$ \\
\hline $46, X X, \operatorname{inv}(6)(p 21.3 p 25)$ & $46, X X, \operatorname{inv}(3)(p 13 p 25)$ \\
\hline $46, X X, \operatorname{inv}(7)(q 11.21 q 21.2)$ & $46, X X, \operatorname{inv}(4)(p 12 q 25)$ \\
\hline $46, X X . i s h$ inv(8)(p21p23) & $46, X X$, inv(4)(p15.2q31.1) \\
\hline $46, X Y, \operatorname{inv}(12)(q 15 q 24.1)$ & $46, X X, \operatorname{inv}(6)(p 23 q 21)$ \\
\hline $46, X Y, \operatorname{inv}(12)(q 15 q 24.1)$ & $46, X X, \operatorname{inv}(8)(p 11.22 q 13.1)$ \\
\hline $46, X Y, \operatorname{inv}(12)(q 15 q 24.1)$ & $46, X Y, \operatorname{inv}(9)(p 13 q 13)$ \\
\hline $46, X Y, \operatorname{inv}(1)(q 21.3 ; q 41)$ & $46, X Y, \operatorname{inv}(5)(p 15.3 q 35)$ \\
\hline
\end{tabular}


Vansenne, F., Borgie, C.A.J.M. de, Korevaar, J.C., Franssen, M.T.M., Pajkrt, E., Hansson, K.B.M/m Leschot, N.J., Bossuyt, P.M.M., Veen, F. van der, Goddijn, M. Low uptake of prenatal diagnosis after established carrier status of a balanced structural chromosome abnormality in couples with recurrent miscarriage. Fertility and Sterility: 2010, 94(1), 296-300

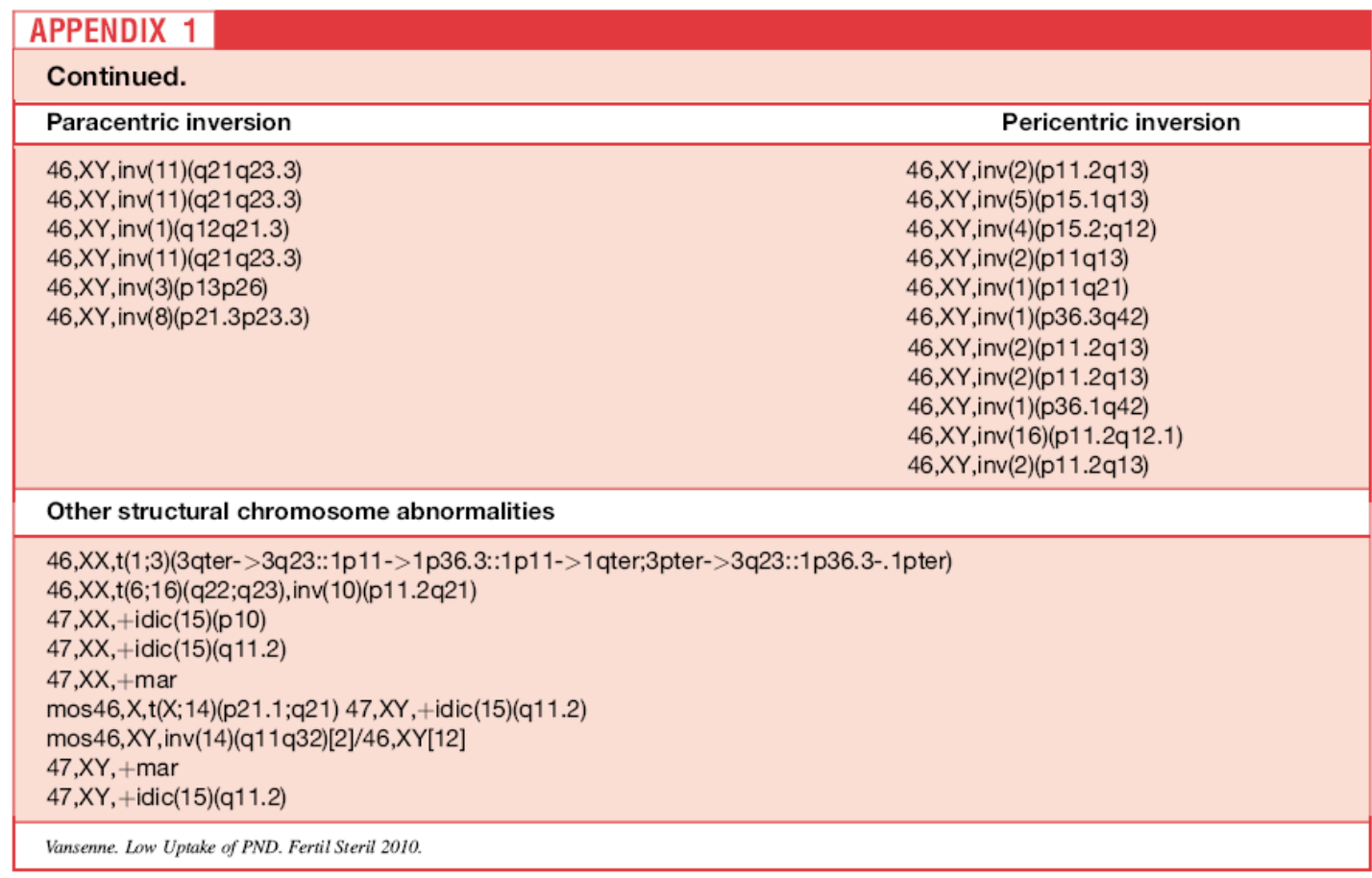

